\title{
Elaboração e avaliação sensorial de sorvete diet e sem lactose de mangaba endêmica do Cerrado
}

\author{
Ana Beatriz da Silva Almeida ${ }^{1}$, Monica Aparecida Campos Ferreira ${ }^{1}$, Thaís Alves Barbosa ${ }^{1}$, \\ Ana Paula Silva Siqueira ${ }^{1}$, Eli Regina Barboza de Souza ${ }^{2}$ \\ ${ }^{1}$ Instituto Federal Goiano - IF Goiano, Campus Morrinhos, Morrinhos, Goiás, Brasil. E-mail: anabiasa14@gmail.com, \\ monicacpferreira@hotmail.com, thais.barbosa@ifgoiano.edu.br, ana.siqueira@ifgoiano.edu.br, eliregina1@gmail.com \\ ${ }^{2}$ Universidade Federal de Goiás - UFV, Escola de Agronomia, Campus Samambaia, Goiânia, Goiás, Brasil. E-mail:
}

Recebido: 15/04/2016; Aceito: 07/07/2016

\section{RESUMO}

A mangaba é um fruto do cerrado, rica em ferro e fonte de vitamina $\mathrm{C}$ mas com alta perecibilidade. Com o objetivo de reduzir os desperdícios e aumentar o processamento desse fruto, foi elaborado um sorvete a partir da polpa do fruto, em uma formulação integral e em outra sem lactose e diet, para atender a consumidores com restrições alimentares. Os sorvetes foram analisados quanto ao $\mathrm{pH}$, sólidos solúveis, acidez titulável e derretimento. E submetidos a análise sensorial por 30 provadores, que mostraram aceitação de ambos, mesmo sendo possível detectar diferença entre eles. A produção de sorvetes é viável para aumentar o processamento de mangaba e evitar desperdícios

Palavras-chave: Mangaba, sorvete, análise sensorial, redução de desperdício

\section{Preparation and sensorial evaluation of lactose-free and diet ice cream of endemic mangaba fruit from Brazilian Cerrado}

\begin{abstract}
Mangaba is a fruit of the cerrado, not much consumed, rich in iron and vitamin $\mathrm{C}$ source but with high perishability. In order to reduce waste and increase the processing of that fruit, an ice cream was prepared from the mangaba pulp one in an integral formulation and another one in lactose-free and diet, to serve consumers with dietary restrictions. The ice creams were submitted to sensorial analysis by 30 tasters, who showed acceptance of both, even being possible to detect differences between them, and also physical-chemical analysis of $\mathrm{pH}$, soluble solids, titratable acidity and melting. The production of ice cream is feasible to increase processing mangaba and avoid waste.
\end{abstract}

Key words: Mangaba, ice cream, sensorial analysis, waste reduction. 


\section{Introdução}

É sabido que um amplo número de espécies vegetais está se perdendo antes mesmo de serem conhecidas pela humanidade. Entretanto, a flora do cerrado possui numerosas espécies frutíferas com potencial de utilização agrícola. A mangabeira (Hancornia speciosa Gomes) é uma planta frutífera de clima tropical, nativa do Brasil e encontrada em várias regiões do País, desde os Tabuleiros Costeiros e Baixada Litorânea do Nordeste até os Cerrados das regiões Centro-Oeste, Norte e Sudeste. É uma das frutas mais ricas em ferro, sendo também uma boa fonte de vitamina C (SILVA JÚNIOR, 2004). Esse fruto apresenta comportamento típico climatérico (ALVES et al., 2006), polpa branca, agridoce e aromática, podendo ser consumida in natura ou no preparo de produtos (BORGES et al., 2000). É um fruto extremamente perecível e representa um sério obstáculo para a comercialização (CARNELOSSI et al., 2004).

Os frutos de mangaba endêmicos do cerrado ainda incorrem em perdas em virtude do curto período de safra, da ausência de uma coloração específica que identifique o fruto maduro e de sua alta perecibilidade, o que compromete seu escoamento e produção (EMBRAPA, 2007). Por esse motivo o maior uso desse fruto é por meio de processamento de polpa congelada. O sorvete é um produto processado bem aceito na mesa dos brasileiros e seu consumo vem crescendo nos últimos anos. Consiste em um sistema coloidal complexo, que forma uma emulsão com gotículas de gordura, proteínas, bolhas de ar e cristais de gelo dispersos em uma fase aquosa, representada por uma solução concentrada de sacarose. Nessa emulsão, podem, ainda, ser inseridos outros ingredientes, desde que não descaracterizem o produto e mantenham a suspensão durante e após o congelamento. Devido às suas propriedades nutricionais, consiste em uma excelente fonte de energia. (SANTOS, 2009; BRASIL, 2005).

Apesar do sorvete e doces em geral serem bem aceitos e muito consumidos, atualmente há uma demanda por produtos especiais para atender consumidores com alguma restrição alimentar como os diabéticos e os intolerantes a lactose que é a má absorção da lactose, ocorre por conta da inatividade ou ineficiência da enzima lactase (ALM, 1982), enquanto o uso de frutose na dieta de diabéticos foi preconizado desde 1893, quando Minkowski observou a independência da frutose em relação à insulina para a sua metabolização. Vários estudos posteriores reforçaram a ideia de que a frutose, assim como o sorbitol, seriam benéficos na dieta de diabéticos (SPARKS, 1992).

Diante do exposto e considerando a necessidade de processamento das mangabas endêmicas do cerrado para reduzir os desperdícios objetivou-se com este estudo elaborar um sorvete de mangaba sem lactose e diet.

\section{Material e Métodos}

Os sorvetes foram elaborados a partir da polpa dos frutos de mangaba já congelada. A polpa foi obtida de frutos colhidos ao chão (considerados amadurecidos) selecionados sem danos, lavados, sanitizados com cloro $200 \mathrm{ppm}$ e processados inteiros com semente e casca em processador multifuncional. A polpa obtida já separada e refinada pela peneira acoplada ao processador foi congelada a $-16{ }^{\circ} \mathrm{C}$.

Foram obtidas duas misturas de sorvete a partir dessa polpa, a primeira contendo $500 \mathrm{~mL}$ de leite integral UHT (Ultra High Temperature), $150 \mathrm{~g}$ de polpa de mangaba, $100 \mathrm{~g}$ de açúcar e $5 \mathrm{~g}$ de liga neutra. A segunda foi elaborada com $500 \mathrm{~mL}$ de leite sem lactose UHT, $150 \mathrm{~g}$ de polpa de mangaba, $50 \mathrm{~g}$ de frutose (conforme a instrução do fabricante seu poder edulcorante é o dobro da sacarose) e $5 \mathrm{~g}$ de liga neutra. Ambas as misturas foram congeladas a $-16{ }^{\circ} \mathrm{C}$ para elaboração do sorvete. Após 24 horas de congelamento as misturas foram batidas em sorveteira com $3 \mathrm{~g}$ de emulsificante até dobrar de volume (incorporação de ar/overrun) e controlar o tamanho dos cristais de gelo formados. Os sorvetes permaneceram armazenados a $16{ }^{\circ} \mathrm{C}$ por mais 24 horas.

As avaliações físico-químicas dos sorvetes observaram: determinação do teor de sólidos solúveis totais por meio da leitura dos graus Brix da amostra a $20^{\circ} \mathrm{C}$, em refratômetro digital (Atago N-1E), de acidez total titulável determinada por titulação, com solução de hidróxido de sódio $(\mathrm{NaOH}) \quad 0,1 \mathrm{~N}$ e pH conforme a AOAC (2010), analisou-se também, a velocidade de derretimento das formulações em gramas por hora.

Aspectos e impressões sensoriais dos sorvetes foram avaliados com 30 provadores através de teste triangular para deteç̧ão de pequenas diferenças entre as amostras, teste de preferência para manifestar a preferência em relação aos produtos oferecidos e escala de intenção onde o consumidor expressa sua vontade de consumir o produto de 1 (nunca consumiria) a 7 (consumiria sempre).

A dados foram submetidos à análise de variância (ANOVA) e as médias dos tratamentos foram comparados pelo teste de Tukey à $5 \%$ de probabilidade.

\section{Resultados e Discussão}

Em relação a cor dos sorvetes ambas as formulações tiveram a coloração final branca. Mas, o derretimento da formulação tradicional foi mais rápido (cerca de $100 \mathrm{~g}$ em 40 minutos) que da formulação sem lactose e diet (60 g em 40 minutos). A taxa de derretimento influencia 
a qualidade final do sorvete, pois ela está intimamente ligada a uma adequada resistência e uma boa cremosidade, sendo um parâmetro importante em sorvete (SOUZA et al, 2010).

Os sólidos solúveis dos sorvetes de mangaba foram diferentes significativamente sendo que o sorvete de mangaba tradicional apresentou teor maior ( $24{ }^{\circ}$ Brix $)$ que o apresentado para a formulação sem lactose e diet (18 Brix) já esperado pela substituição da sacarose por um açúcar simples. O açúcar é considerado um ingrediente importante na formulação de sorvetes, devido ao seu efeito sobre sabor, elevando assim a aceitação do produto, além disso, possui o papel de aumentar o teor de sólidos e viscosidade podendo tornálo mais cremoso. No entanto, é importante avaliar que a frutose tem o poder edulcorante maior que o da sacarose e, portanto, essa redução de sólidos não significa redução da doçura do produto.

Outro parâmetro importante quanto à formulação do sorvete é sua acidez, que inclusive pode influenciar na pigmentação desse alimento. $\mathrm{O} \mathrm{pH}$ do sorvete com formulação especial foi ligeiramente maior $(6,27)$ que do sorvete tradicional $(5,81)$. Em relação à acidez, a formulação tradicional teve a acidez maior, coerente com seu pH (0,19 mg ácido cítrico/ $100 \mathrm{~g})$, que a formulação sem lactose e diet $(0,11 \mathrm{mg}$ ácido cítrico/ $100 \mathrm{~g})$. O pH e acidez de sorvetes, em geral está diretamente relacionado aos saborizantes utilizados, no entanto, neste caso o único saborizante foi a própria polpa de mangaba, a acidez média da polpa de mangaba foi aproximadamente 0,74 . $\mathrm{O} \mathrm{pH}$ está relacionado às características gustativas dos sucos e pode ser influenciado principalmente pela variabilidade genética de diferentes cultivares ou da região onde são colhidos os frutos (PEYNAUD, 1997).

Para acidez titulável e $\mathrm{pH}$, não existem valores de referência determinados pela legislação. Segundo Correia (2008), o pH e acidez titulável dos sorvetes são parâmetros influenciados pelo sabor empregado na formulação, sendo que sorvetes de frutas normalmente possuem acidez diferenciada de sorvetes de chocolate ou de creme.

Cerca de $77 \%$ dos provadores detectaram diferenças entre as formulações. Quando questionados sobre o potencial de consumo do produto de cada formulação a média para o sorvete tradicional foi de 6 e para o sorvete sem lactose e diet foi de 4 . Como a escala variou de 1 a 7 considera-se que ambos os sorvetes possuem boa aceitação entre consumidores, mesmo a formulação sem lactose e diet. Questionados sobre preferência cerca de $43 \%$ dos provadores declararam preferir a formulação sem lactose e diet.

Produtos sem lactose e diet desenvolvidos para atender o mercado se aproximam muito em sabor e aparência, como nesse estudo, das formulações tradicionais. Logo, a aceitação dos consumidores é mais facilitada. A substituição da sacarose pela frutose influencia nessa preferência já que o açúcar está intimamente ligado ao sabor dos produtos. No entanto, nota-se que o mercado já tem se preparado para receber esses produtos sem lactose e diet, mesmo porque doenças que causam restrições alimentares estão se desenvolvendo, e produtos mais saudáveis estão sendo uma necessidade do consumidor.

\section{Conclusões}

A elaboração de sorvetes é uma boa opção para o processamento de mangaba e aumento em seu consumo e comercialização. $O$ sorvete foi bem aceito pelos provadores, incluindo sua formulação sem lactose e diet, mesmo sendo perceptível diferença entre as formulações. Com isso, esse estudo comprovou que o desperdício de mangaba, devido sua alta perecibilidade, pode ser reduzido através da produção de sorvetes, seja ela tradicional, ou para atender a consumidores com restrições alimentares.

\section{Referências Bibliográficas}

ALM, L. Effect of fermentation on lactose, glucose, and galactose content in milk and suitability of fermented milk products for lactose intolerant individuals. Journal of Dairy Science, Champaign, v. 65, n. 3, p. 346-352, 1982.

ALVES, R. E. LEMOS, R.P.; OLIVEIRA, E.F.; SILVA, H.; SILVA, A.Q.; MALAVOLTA, E. A cultura da mangaba. Aracaju-SE: Embrapa Tabuleiros Costeiros, 2006. Cap.16, p. 207-220.

AOAC. ASSOCIATION OFFICIAL ANALYTICAL CHEMISTIS. Official Methods of Analysis of AOAC International. $18^{\text {th }}$. ed. Gaithersburg: AOAC, 2010.

BORGES, M. F.; FILGUEIRAS, H. A. C.; MOURA, C. F. H. Mangaba (Hancornia speciosa Gomes). In: ALVES, R. E.; FILGUEIRA, H. A. C.; MOURA, C. F. H. (Eds.). Caracterização de frutas nativas da América Latina. (Série Frutas Tropicais). Jaboticabal-SP: FUNEP, 2000. cap. 12, p. 44-45.

BRASIL. Ministério da Saúde. Secretaria de Vigilância Sanitária. Resolução RDC n. 266, 22 de setembro de 2005. Aprova o regulamento de gelados comestíveis e preparados para gelados comestíveis. Diário Oficial [da República Federativa do Brasil] Brasília, DF, 23 set. 2005.

CARNELOSSI, M. A. G.;TOLEDO, W. F. F.; SOUZA, D. C. L.; LIRA, M. L.; SILVA, G. F.; JALALI, V. R. R.; VIÉGAS, P. R. A. Conservação pós-colheita de mangaba (Hancornia speciosa Gomes). Revista Ciência e Agrotecnologia, LavrasMG, v. 28, n. 5, p. 1119-1125, 2004

CORREIA, R. T. P.; MAGALHÃES, M. M. A.; PEDRINI, M. R. S.; CRUZ, V. F.; CLEMENTINO, T. Sorvetes elaborados com leite caprino e bovino: Composição química e 
propriedades de derretimento. Revista Ciência Agronômica, Fortaleza-CE, v. 39, n. 02, p. 251-256, 2008

EMPRAPA. EMPRESA BRASILEIRA DE PESQUISA AGROPECUÁRIA. Sistema de produção da mangaba para os tabuleiros costeiros e baixadas litorâneas. Versão eletrônica, nov/2007. Disponível em: http://sistemasdeproducao.cnptia.embrapa.br/FontesHTML/M angaba/SistemaProducaoMangabaTabuleirosCosteiros/Introdu cao.html. Acesso em: mar. 2015.

PEYNAUD, E. Connaissance et travail du vin. 2 ed. Paris: Dunod, 1997. $341 \mathrm{p}$.

SANTOS, G. G. Sorvete: processamento, tecnologia e substitutos de sacarose. Ensaios e Ciencia, Campo GrandeMS, v.13, n. 2, p. 95-109, 2009.
SILVA JUNIOR, J. F. A cultura da Mangaba. Revista Brasileira de Fruticultura, Jaboticabal-SP, v. 26, n. 1, p. 1192, 2004.

SOUZA, J. C. B; COSTA, M. R; DE RENSIS, C. M. V. B; SIVIERI, E. Sorvete: composição, processamento e viabilidade da adição de probiótico. Alimentos e Nutrição. Araraquara-SP, v. 21, n.1, p. 155-165, 2010.

SPARKS, J. W. Galactose and fructose. In: POLIN, R. A; FOX, W. W. Fetal and neonatal physiology. Philadelphia: Saunders; 1992. p. 384-90. 